\title{
Composition of Lipopolysaccharides from Alteromonas putrefaciens (Shewanella putrefaciens)
}

\author{
By ANNE L. MOULE AND STEPHEN G. WILKINSON* \\ Department of Chemistry, University of Hull, Hull HU6 7RX, UK
}

(Received 25 July 1988; accepted 12 October 1988)

\begin{abstract}
Lipopolysaccharides from eight strains of Alteromonas putrefaciens (Shewanella putrefaciens) representing four groups defined by DNA-DNA homology studies have been compared. All products were of the R-type, lacking a polymeric side chain. In each case lipid A was based on glucosamine and contained a complex range of fatty acids. In general, the major non-hydroxy acids were 11-methyldodecanoic acid and tridecanoic acid, and the major hydroxy acids were 3hydroxyundecanoic acid, 3-hydroxydodecanoic acid, 3-hydroxy-11-methyldodecanoic acid, 3hydroxytridecanoic acid and 3-hydroxytetradecanoic acid. All lipopolysaccharides contained a 3-deoxy-2-octulosonic acid, only detectable after dephosphorylation. All core oligosaccharides contained D-galactose and D-glycero-D-manno-heptose, and all except those of group I strains also contained D-galactosamine. Group I strains (including NCIB 10471, the type strain) were distinguished from others by the presence in the core of 3-amino-3,6-dideoxyglucose, D-glucose, and acid-stable phosphate residues. Quinovosamine and D-fructose were found only in group IV strains. Core oligosaccharides from the group II and group III strains, as isolated, were deficient in heptose and seemed to have the same structure. During mild acid hydrolysis of the lipopolysaccharides, various monosaccharides and phosphates were released. The monosaccharides were D-galactose (group I), D-fructose (group IV), and D-galacturonic acid (mainly groups II and III). Phosphates identified were ethanolamine pyrophosphate, ethanolamine phosphate, pyrophosphate, and orthophosphate. The chemotaxonomic implications of the results are discussed.
\end{abstract}

\section{INTRODUCTION}

The pseudomonad-like bacteria currently known as Alteromonas putrefaciens (Lee et al., 1981) or Shewanella putrefaciens (MacDonell \& Colwell, 1985) have diverse habitats (Lee, 1979). The bacteria include, inter alia, marine and clinical isolates and organisms responsible for the spoilage of cold-stored, protein-rich foods. Their phenotypic and genotypic heterogeneity is well documented (e.g. Lee, 1979; Owen et al., 1978; Gilardi, 1985), and their taxonomy remains uncertain (Baumann et al., 1984), although a phylogenetic location within subgroup $\gamma-3$ of the purple bacteria has been proposed (Woese et al., 1985). On the basis of DNA-DNA homology studies (Owen et al., 1978), four groups of strains have been recognized: members of the two most clearly circumscribed groups (I and IV) can be differentiated by their DNA base composition and various phenotypic properties.

The extensive studies of bacterial lipopolysaccharides (LPSs) have provided numerous examples of chemotaxonomic applications of compositional and structural data, but little work has been done with alteromonads. However, a study of the LPSs from five strains of $\boldsymbol{A}$. putrefaciens (Wilkinson \& Caudwell, 1980) showed their fatty acid compositions to be exceptionally complex. Earlier studies (Wilkinson et al., 1973) of the LPS from strain

Abbreviations: KDO, 2-keto-3-deoxyoctonic acid (3-deoxy-D-manno-2-octulosonic acid); LPS, lipopolysaccharide. 
NCIB 8768 (then known as Pseudomonas rubescens) showed that it was of the R-type, and that it contained acid-labile galactose residues but possibly no 2-keto-3-deoxyoctonic acid (KDO). Another unusual feature (Wilkinson, 1977) was the presence in the core oligosaccharide of Dglycero-D-manno-heptose (or its enantiomer) rather than the more common isomer L-glycero-Dmanno-heptose. These results, taken with our failure to discriminate clearly between members of the four groups of $A$. putrefaciens by their polar lipid, fatty acid, and isoprenoid quinone compositions (Moule \& Wilkinson, 1987), led us to carry out comparative analyses of LPSs from strains representing all four groups.

\section{METHODS}

Bacterial strains. Single strains representing each of the DNA-DNA homology groups of $A$. putrefaciens (Owen et al., 1978) were studied in detail: NCIB 10471 (group I), NCIB 10472 (group II), NCIB 10473 (group III), and NCTC 10763 (group IV). Other strains studied more briefly were NCIB 8768 (group I), NCTC 10737 (group II), NCTC 10738 (group IV), and NCIB 11156 (group unknown).

Growt of bacteria, and extraction and fractionation of LPSs. Organisms were grown for $24 \mathrm{~h}$ at $30{ }^{\circ} \mathrm{C}$ in nutrient broth (20 1, Oxoid CM67) with aeration at $201 \mathrm{~min}^{-1}$ and stirring at 300 r.p.m. Cells were disintegrated in a DynoMill KDL (W. A. Bachofen AG, Basel), and LPS was extracted from purified, defatted cell walls (Wilkinson et al., 1973) by treatment with $45 \%(\mathrm{w} / \mathrm{v})$ aqueous phenol for $15 \mathrm{~min}$ at $68{ }^{\circ} \mathrm{C}$. Water-soluble products obtained by hydrolysis of the LPS with $1 \%(\mathrm{v} / \mathrm{v})$ acetic acid at $100^{\circ} \mathrm{C}$ for $1-2 \mathrm{~h}$ were fractionated by chromatography on Sephadex G-50 or G-15, using pyridine/acetic acid buffer of pH 5.4 as the eluent (Wilkinson et al., 1973). Eluates were screened for phosphorus and for carbohydrate (phenol/ $\mathrm{H}_{2} \mathrm{SO}_{4}$ method).

Paper chromatography and high-voltage electrophoresis. Paper chromatography and electrophoresis (Shandon) were carried out with Whatman no. 1 paper. The following solvent systems were used: A, ethyl acetate/pyridine/water (13:5:4, by vol.); B, ethyl acetate/pyridine/water/acetic acid $(5: 5: 3: 1$, by vol.); C, ethyl acetate/acetic acid/water (3:1:3, by vol.; upper phase); D, $95 \%(v / v)$ ethanol/1 M-ammonium acetate $(7: 3$, by vol.); E, butan-1-ol/acetic acid/water ( $62: 15: 25$, by vol.). Buffer systems used for electrophoresis were as follows: F, pyridine/acetic acid/water $(5: 3: 43$, by vol.; $\mathrm{pH} 5 \cdot 3) ; \mathrm{G}$, as F but containing 0.01 M-EDTA; H, pyridine/acetic acid/water $(1: 10: 89$, by vol., adjusted to $\mathrm{pH} 2 \cdot 7$ with formic acid). In addition to general reagents (ninhydrin, alkaline $\mathrm{AgNO}_{3}$, aniline hydrogen oxalate, and the periodate/Schiff reagents) used for the detection of basic, neutral or acidic monosaccharides, the periodate/thiobarbituric acid reagents were used for the detection of KDO (Warren, 1960), and a series of reagents ( $\alpha$-naphthol $/ \mathrm{HCl}, \alpha$-naphthol $/ \mathrm{H}_{3} \mathrm{PO}_{4}$, orcinol $/ \mathrm{HCl}, \mathrm{urea} / \mathrm{HCl}$, and anthrone $/ \mathrm{H}_{3} \mathrm{PO}_{4}$ ) was used for the detection of fructose (Dawson et al., 1986). Phosphates were detected by using molybdate-based reagents (Hanes \& Isherwood, 1949; Mann et al., 1979).

$T L C$. This was done with layers of cellulose, silica gel G, or silica gel $60 \mathrm{~F}_{254}$ (all Merck). Solvent systems used were as follows: I, dichloromethane; J, dioxan/water/trichloroacetic acid/18 M-ammonia $(260: 110: 20: 1$, by vol.); $\mathrm{K}$, acetone/water ( $9: 1$, by vol.); L, butan-1-ol/acetone/water (4:5:1, by vol.); M, propan-2-ol/acetone/water ( $4: 5: 1$, by vol.). Components were detected by using $I_{2}$ vapour (fatty esters) or reagents described for paper chromatography and electrophoresis.

GLC. GLC separations were carried out by using either packed columns (Silar 10C or OV-275) in a Pye Unicam chromatograph, or a fused-silica capillary column $(25 \mathrm{~m})$ of BP1 (Scientific Glass Engineering, Milton Keynes, UK). Combined GLC/MS was done with a Finnigan 1020B instrument.

Ion-exchange chromatography. A Locarte instrument was used for the autoanalysis of amino compounds. Amino sugars were also characterized and isolated by chromatography on a column $(0.9 \mathrm{~cm} \times 46 \mathrm{~cm})$ of Bio-Rad $50 \mathrm{~W} \times 8 \mathrm{resin}\left(\mathrm{H}^{+}\right.$form), using $0.33 \mathrm{M}-\mathrm{HCl}$ as the eluent (Crumpton, 1959). Fractions (2 $\left.\mathrm{ml}\right)$ were screened for amino sugars by using either ninhydrin or the $\mathrm{HNO}_{2}$ /indole method (Ohno et al., 1985).

$N M R$. ${ }^{1} \mathrm{H}$ NMR spectra were obtained with a JEOL JNM-GX270 spectrometer. For amino sugars in ${ }^{2} \mathrm{H}_{2} \mathrm{O}$, spectra were recorded at $70^{\circ} \mathrm{C}$ with sodium 4,4-dimethyl-4-silapentane-1-sulphonate as an external reference. For amino sugar acetates in $\mathrm{C}^{2} \mathrm{HCl}_{3}$, spectra were recorded at $21^{\circ} \mathrm{C}$ with tetramethylsilane as an internal reference.

Identification of neutral sugars. Samples were hydrolysed with $2 \mathrm{M}-\mathrm{HCl}$ at $105^{\circ} \mathrm{C}$ for $2 \mathrm{~h}$, and the hydrolysates were neutralized and deionized with ion-exchange resins. Sugars were identified by paper chromatography (solvent systems A and C) and by GLC of the alditol acetates (Silar 10C, OV-275, or BP1), which also provided quantitative data (corrected for losses during hydrolysis or work-up). Fructose, released by mild acid hydrolysis of LPS, was identified by the above methods, by TLC (solvent systems $K, L$, and M), and by colorimetric assays (see below). D-Glucose, D-galactose and D-fructose were also identified and estimated by enzymic assays (see below). In some cases, confirmation of sugar composition was obtained by GLC of the methyl glycoside trifluoroacetates (Bryn \& Jantzen, 1986).

Identification of acidic sugars. Hexuronic acids were separated by paper chromatography (solvent system B) and electrophoresis (buffer systems F and H). D-Galacturonic acid (isolated by preparative paper electrophoresis) was 
identified by using D-galactose oxidase (EC 1.1.3.9) after glycosidation/esterification with methanolic $2 \mathrm{M}-\mathrm{HCl}$ $\left(60^{\circ} \mathrm{C}, 2 \mathrm{~h}\right)$, followed by reduction with $\mathrm{NaBH}_{4}$ and acid hydrolysis. Attempts to detect $\mathrm{KDO}$ were made by paper electrophoresis (buffer system F) of mild acid hydrolysates, by GLC and GLC/MS of trifluoroacetylated methanolysates (Bryn \& Jantzen, 1986), and by colorimetric assay (see below).

Identification of amino sugars. Amino compounds were identified and estimated by autoanalysis after hydrolysis of samples with $4 \mathrm{M}-\mathrm{HCl}$ at $105^{\circ} \mathrm{C}$ for $6 \mathrm{~h}$. Hydrolysates were also examined by TLC and paper chromatography (solvent system B), paper electrophoresis (buffer system F), and ion-exchange chromatography (see above). Isolated amino sugars were also characterized as 2,5-anhydrohexitol acetates by GLC after initial deamination (Lindberg \& Lönngren, 1978), and by GLC and MS of the aminoalditol acetates. The Rondle \& Morgan (1955) test was used for 2-amino sugars and a modification (Ashwell et al., 1965) of the test for 3-amino sugars. DGalactosamine was identified by using D-galactose oxidase (Sempere $e$ al., 1965). ${ }^{1} \mathrm{H}$ NMR spectra were used to assist in the identification of two unusual amino sugars (free or as the peracetates).

Identification of phosphates. Pyrophosphate ( $\mathrm{PP}_{\mathrm{i}}$ ) was identified by paper electrophoresis (buffer system $\mathrm{G}$ ), TLC (solvent system $\mathbf{J}$ and cellulose plates), and by treatment with inorganic pyrophosphatase (EC 3.6.1.1) as described previously (Drewry et al., 1972). Ethanolamine phosphate (O-phosphoethanolamine) and ethanolamine pyrophosphate ( $O$-diphosphoethanolamine) were similarly identified by paper electrophoresis and by dephosphorylation with alkaline phosphatase (EC 3.1.3.1) as in earlier studies (Drewry et al., 1971, 1972). Reference ethanolamine pyrophosphate was prepared by the reaction of 2-bromoethylamine with $\mathrm{Na}_{4} \mathrm{P}_{2} \mathrm{O}_{7}$ (each $25 \mathrm{mM}, \mathrm{pH} 9.0$ ) at $37^{\circ} \mathrm{C}$ for $40 \mathrm{~h}$. In order to detect KDO masked by phosphorylation, LPS was treated with $49 \%$ (w/w) $\mathrm{HF}$ at $4^{\circ} \mathrm{C}$ for $48 \mathrm{~h}$ (Caroff et al., 1987a).

Identification of fatty acids. Faity acids were released from LPS by hydrolysis with $4 \mathrm{M}-\mathrm{HCl}$ at $105^{\circ} \mathrm{C}$ for $6 \mathrm{~h}$, extracted into diethyl ether, and esterified by using diazomethane. Methyl esters were fractionated by TLC (solvent system I), and were identified by GLC and GLC/MS (column BP1). Trifluoroacetylation (Bryn \& Jantzen, 1986) was used to confirm hydroxy esters.

Quantitative analyses. Total phosphorus was determined by the method of Bartlett (1959) and orthophosphate $\left(\mathrm{P}_{\mathrm{i}}\right)$ by the method of Parvin \& Smith (1969). Total carbohydrate (expressed as galactose) was determined by the phenol/ $/ \mathrm{H}_{2} \mathrm{SO}_{4}$ method (Dubois et al., 1956), heptose by the cysteine/ $\mathrm{H}_{2} \mathrm{SO}_{4}$ method (Wright \& Rebers, 1972), and $\mathrm{KDO}$ by the periodate/thiobarbituric acid method (Osborn, 1963). The 3-hydroxybiphenyl/ $\mathrm{H}_{2} \mathrm{SO}_{4}$ method (Blumenkrantz \& Asboe-Hansen, 1973) was used to determine total hexuronic acid. Three different 'ketosespecific' colorimetric assays were used for the determination of fructose (Dische \& Borenfreund, 1951; van Handel, 1967; Boratyński, 1984). D-Glucose was determined either by using D-glucose oxidase (EC 1.1.3.4) or by using the combination of hexokinase (EC 2.7.1.1) with D-glucose-6-phosphate dehydrogenase (EC 1.1.1.49). The latter combination together with phosphoglucose isomerase (EC 5.3.1.9) was used for the assay of Dfructose. D-Galactose, D-galactosamine, and (indirectly) D-galacturonic acid were determined by using D-galactose oxidase. Total fatty acid (expressed as hexadecanoic acid) was determined by the method of Itaya \& Ui (1965).

SDS-PAGE. Samples of LPS were examined by SDS-PAGE using $15 \%(\mathrm{w} / \mathrm{v})$ polyacrylamide separating gels and silver staining according to standard procedures summarized by Helander (1985).

\section{RESULTS}

\section{General properties of the LPSS}

LPSs were obtained from defatted cell walls by using hot aqueous phenol, and were recovered from the dialysed aqueous phase without deposition by ultracentrifugation. Yields were in the range 9 to $15 \%$ of the defatted walls. These rather low yields are at least partly explained by the absence from the LPSs of a polymeric side chain (see below). Although R-type LPS is relatively lipophilic, little additional material was recovered from the phenolic phase of the extract for strain NCIB 10472 (which had given the lowest yield of LPS) after dialysis, removal of the precipitate formed, and freeze-drying of the residual solution. SDS-PAGE of four representative LPSs (from strains NCIB 10471, NCIB 10472, NCIB 10473 and NCTC 10763) showed only a fast-moving band in the region expected for R-type LPS. Gel-permeation chromatography of the water-soluble products from mild acid hydrolysis of all eight LPSs confirmed the absence of a polymeric fraction, and hence of S-type LPS.

General analytical data for the LPSs from representative strains of different DNA-DNA homology groups are given in Table 1 . All of the products were rich in phosphorus and fatty acids, again consistent with an R-type of LPS. The total carbohydrate contents (excluding amino sugars) were only modest, and the monosaccharide compositions (discussed below) were relatively simple. Ethanolamine was present in each LPS studied. 
Table 1. Composition $(\%, w / w)$ of the LPSs

\section{Component}

\section{Phosphorus}

Fatty acid

Total carbohydrate

D-Fructose

D-Galactose*

D-Glucose*

Heptose

KDO:

Hexuronic acid

Glucosamine§

D-Galactosamine

3-Amino-3,6-dideoxyglucose\|

Quinovosamine $\|$

Ethanolamine
Strain (DNA-DNA homology group):

$\overbrace{\begin{array}{c}\text { NCIB 10471 } \\ \text { (group I) }\end{array}}^{\begin{array}{c}\text { NCIB 10472 } \\ \text { (group II) }\end{array}} \underbrace{\begin{array}{c}\text { NCTC 10763 } \\ \text { (group IV) }\end{array}}_{\begin{array}{c}\text { NCIB 10473 } \\ \text { (group III) }\end{array}}$

$\begin{array}{cc}4 \cdot 6 & 4 \cdot 5 \\ 42 \cdot 2 & 27 \cdot 3 \\ 15 \cdot 0 & 17 \cdot 3 \\ 0 & 0 \\ 11 \cdot 0(10 \cdot 6) & 10 \cdot 8(12 \cdot 0) \\ 5 \cdot 0 & 0 \\ 8 \cdot 7 & 7 \cdot 4 \\ 0 \cdot 26(0 \cdot 90) & 0 \cdot 25(0 \cdot 40) \\ 0 & \text { Trace } \\ 6 \cdot 1 & 6 \cdot 1 \\ 0 & 3 \cdot 8 \\ 3 \cdot 4 & 0 \\ 0 & 0 \\ + & +\end{array}$

$4 \cdot 2$
$36 \cdot 4$
$18 \cdot 5$
0
$10 \cdot 9(11 \cdot 9)$
0
$6 \cdot 5$
$0 \cdot 22(0 \cdot 30)$
+
$6 \cdot 5$
$3 \cdot 9$
0
0
+

$4 \cdot 5$

$37 \cdot 8$

$19 \cdot 3$

$+$

$7.5(7 \cdot 0)$

Trace

$5 \cdot 7$

$0 \cdot 26(1 \cdot 10)$

$+$

$4 \cdot 7$

3.5

0

$0 \cdot 4$

$+$

*Values in parentheses were obtained by enzymic assay, other values by GLC.

$\dagger$ Expressed as L-glycero-D-manno-heptose.

Values in parentheses were obtained for HF-treated LPSs, other values for the native products.

$\S$ Values exclude glucosamine phosphate(s) also present in hydrolysates.

$\|$ Expressed as glucosamine.

\section{Monosaccharide compositions of the LPSS}

Neutral monosaccharides. D-Galactose and an aldoheptose with the chromatographic properties of D-glycero-D-manno-heptose (or its enantiomer) were present in all LPSs, but D-glucose was only a significant component for strain NCIB 10471 (Table 1) and the other group I strain NCIB 8768 (Wilkinson et al., 1973).

Although colorimetric assays indicated heptose contents in the range 6 to $9 \%$, peak areas on GLC of the heptitol acetate were relatively low for the LPSs from group I strains, suggesting extensive phosphorylation of the heptose in these cases. In confirmation of this inference, heptose was found as a major component of the LPS from strain NCIB 10471, by GLC and MS of the trifluoroacetylated methyl glycosides (Bryn \& Jantzen, 1982), only after HFdephosphorylation of the LPS.

Fructose was not detected in acid hydrolysates of LPSs (probably because of destruction under the conditions used), but subsequent studies (see below) revealed the presence of the ketose for strain NCTC 10763 (Table 1) and strain NCTC 10738 (the other group IV strain).

Acidic monosaccharides. As previously reported for strain NCIB 8768 (Wilkinson et al., 1973), little or no colour was produced in the periodate/thiobarbituric acid assay for KDO by any LPS from $A$. putrefaciens. Similarly, KDO was not detected by GLC of the trifluoroacetylated methanolysis products (Bryn \& Jantzen, 1986), nor by paper electrophoresis of low- $M_{\mathrm{r}}$ products released on mild acid hydrolysis of the LPSs. However, after HF treatment of the LPSs (Caroff et al., 1987a), modest but significant increases in the apparent KDO contents were found (Table 1), and the typical pink colour for the assay was visible in all cases. By means of GLC and MS of the trifluoroacetylated methanolysis products from HF-treated LPS from strain NCIB 10471, the presence of KDO was confirmed. One major peak was observed on GLC, and diagnostic fragment ions (Bryn \& Jantzen, 1986) with $\mathrm{m} / z$ 631, 619, 591, 477, 363, 277 and 249 were observed by MS.

Colorimetric assay for hexuronic acids gave results of less than $1 \%$ for all LPSs. However, further studies of mild acid hydrolysates showed the presence of significant amounts of galacturonic acid (identified as the D isomer for strain NCIB 10473) for strains NCIB 10473, NCIB 11156 and NCTC 10737. The same hexuronic acid was also detected for the LPS of strain NCTC 10763, while a trace of glucuronic acid was detected for strain NCIB 10472. 
Basic monosaccharides. All four representative LPSs (Table 1) contained glucosamine (configuration not determined but expected to be $D$ ), while galactosamine (shown to be the $D$ isomer for strain NCTC 10763) was present in three of the LPSs (that from strain NCIB 10471 being the exception).

In addition, two other amino sugars were encountered. Unknown A, present only in strain NCIB 10471 , had $m_{\mathrm{GalN}}$ about $1 \cdot 1$ on paper electrophoresis at $\mathrm{pH} 5 \cdot 3, R_{\mathrm{GalN}}$ about 1.4 on paper chromatography (solvent system B), an elution volume of about 1.3 relative to glucosamine on Bio-Rad AG 50, and was eluted from the autoanalyser in about the position of fucosamine (6-deoxygalactosamine). However, the $N$-acetyl derivative only gave a positive Morgan/Elson reaction after periodate oxidation, which suggested that unknown $A$ was a 3-amino-3deoxyhexose (Ashwell et al., 1965). This inference was confirmed by MS of the aminodeoxyhexitol acetate, which gave fragment ions with $m / z 216,156$ and 96 , arising from fission of the bond between C-3 and C-4. Further fragment ions with $m / z$ 230, 170, 128 and 110 (arising from fission of the bond between C-2 and C-3) indicated that unknown A was actually a 3-amino-3,6dideoxyhexose (e.g. Banoub \& Shaw, 1981 ; L'vov et al., 1983; Seltmann \& Beer, 1985). The 6deoxy group was confirmed by the ${ }^{1} \mathrm{H}$ NMR spectrum of the monosaccharide which contained, inter alia, anomeric signals at $\delta 5 \cdot 19\left(J_{1,2} 3.7 \mathrm{~Hz}\right)$ and $4.67\left(J_{1,2} 7.8 \mathrm{~Hz}\right)$ corresponding to the $\alpha$ and $\beta$-pyranose forms, respectively, of a monosaccharide with $\mathrm{H}-2$ axial, and the respective methyl signals at $\delta 1.25$ and 1.29 (each with $J_{5,6} 6 \cdot 1 \mathrm{~Hz}$ ). The anomeric ratio $(\alpha: \beta)$ was about $1 \cdot 0: 1 \cdot 6$.

Comparison of unknown A with three reference amino sugars by TLC and paper chromatography (solvent system B), by ion-exchange chromatography (Bio-Rad AG 50 and autoanalysis), and by GLC of the aminodeoxyalditol acetates, pointed to its identity as 3-amino3,6-dideoxyglucose and ruled out the isomers with the manno or galacto configuration. The gluco configuration of unknown A was confirmed by further studies of its ${ }^{1} \mathrm{H}$ NMR spectrum (assisted by selective decoupling experiments), which showed that all ring protons in the preponderant $(\beta)$ anomer were axially orientated, and by similar studies of the ${ }^{1} \mathrm{H}$ spectrum of the mixed $\alpha$ - and $\beta$-tetra-acetates, which matched that of the reference mixture and that reported (L'vov et al., 1983).

Unknown B was present in the LPS from strain NCTC 10763 (and also that of the other group IV strain, NCTC 10738). Its high chromatographic mobilities, taken with a positive Morgan/Elson reaction for a 2-amino sugar, suggested that it might be a 2-amino-2,6dideoxyhexose. This was supported by the ${ }^{1} \mathrm{H}$ NMR spectrum which contained, inter alia, anomeric signals of similar integral at $\delta 5.32\left(J_{1,2} 3.5 \mathrm{~Hz}\right)$ and $4.75\left(J_{1,2} 8.5 \mathrm{~Hz}\right)$, again showing $\mathrm{H}-2$ to be axial, as well as methyl doublets $\left(J_{5,6}\right.$ about $\left.6 \mathrm{~Hz}\right)$ at $\delta 1 \cdot 28$ and $1 \cdot 25$. Confirmation of the class of amino sugar was provided by MS of the aminodeoxyalditol acetate (diagnostic fragment ions with $m / z 260,242,144,102$ and 84) and of the acetylated 2,5-anhydro-6deoxyalditol produced by deamination/reduction of the amino sugar (diagnostic fragment ions with $m / z$ 201, 141, 112 and 99; Erbing et al., 1973).

Comparison of unknown B with reference quinovosamine (2-amino-2,6-dideoxyglucose) by TLC and paper chromatography, by autoanalysis, and by GLC of both the aminodeoxyalditol acetate and the 2,5-anhydro-6-deoxyalditol acetate showed identical chromatographic behaviour in all cases. Thus, unknown $B$ appears to be quinovosamine.

\section{Fatty acid compositions of the LPSs}

Fatty acid compositions determined for individual LPSs (Table 2) were broadly similar and resembled those reported previously (Wilkinson et al., 1973; Wilkinson \& Caudwell, 1980) for various strains. The profiles, which include odd-carbon, even-carbon, linear, and branchedchain acids, are unusually complex and are dominated by 3-hydroxy acids. The latter were isolated by TLC of their methyl esters, and were identified by GLC (with the aid of reference compounds for the even-carbon, straight-chain esters), and by MS of the hydroxy esters (giving characteristic peaks with $m / z 103, \mathbf{M}-18$ and M-50, inter alia) and of their trifluoroacetyl derivatives (giving characteristic peaks with $m / z$ M-31, M-145 and M-188, inter alia). Major hydroxy acids in all strains were $3-\mathrm{OH}-11: 0,3-\mathrm{OH}-12: 0,3-\mathrm{OH}-\mathrm{i}-13: 0,3-\mathrm{OH}-13: 0$, and 3-OH- 
Table 2. Fatty acid composition of the LPSs

Results are expressed as percentages of the total peak area from GLC of the methyl esters.

\begin{tabular}{|c|c|c|c|c|}
\hline \multirow[b]{2}{*}{ Fatty acid* } & \multicolumn{4}{|c|}{ Strain: } \\
\hline & NCIB 10471 & NCIB 10472 & NCIB 10473 & NCTC 10763 \\
\hline $11: 0$ & 1.4 & 0.8 & 1.5 & $2 \cdot 1$ \\
\hline $12: 0$ & $4 \cdot 1$ & $3 \cdot 0$ & $2 \cdot 8$ & $2 \cdot 7$ \\
\hline $\mathrm{i}-13: 0$ & 6.7 & $5 \cdot 1$ & $4 \cdot 2$ & $9 \cdot 2$ \\
\hline $13: 0$ & 12.9 & 5.6 & 11.6 & 8.4 \\
\hline $\mathrm{i}-14: 0$ & 0.4 & $2 \cdot 4$ & $1 \cdot 4$ & 1.5 \\
\hline $14: 0$ & 0.4 & 0.4 & 0.6 & 0 \\
\hline $3-\mathrm{OH}-11: 0$ & $13 \cdot 0$ & 8.5 & $11 \cdot 1$ & $10 \cdot 2$ \\
\hline $3-\mathrm{OH}-\mathrm{i}-12: 0$ & Trace & $10 \cdot 0$ & $2 \cdot 3$ & Trace \\
\hline $3-\mathrm{OH}-12: 0$ & $16 \cdot 3$ & 10.8 & 12.9 & $11 \cdot 1$ \\
\hline $3-\mathrm{OH}-\mathrm{i}-13: 0$ & 7.7 & $14 \cdot 1$ & 11.0 & $14 \cdot 2$ \\
\hline $3-\mathrm{OH}-\mathrm{a}-13: 0$ & 0 & 0.7 & Trace & Trace \\
\hline $3-\mathrm{OH}-13: 0$ & $21 \cdot 2$ & $13 \cdot 0$ & $19 \cdot 2$ & 18.0 \\
\hline $3-\mathrm{OH}-\mathrm{i}-14: 0$ & Trace & 7.5 & 1.5 & 1.0 \\
\hline $3-\mathrm{OH}-14: 0$ & $7 \cdot 2$ & 8.7 & $9 \cdot 0$ & 6.6 \\
\hline $3-\mathrm{OH}-\mathrm{i}-15: 0$ & 0.5 & $3 \cdot 4$ & $2 \cdot 3$ & 4.6 \\
\hline $3-\mathrm{OH}-\mathrm{a}-15: 0$ & 0 & 1.6 & 0 & 0 \\
\hline $3-\mathrm{OH}-15: 0$ & Trace & 0.8 & 0.4 & 0.3 \\
\hline Others $†$ & 8.0 & 3.6 & $8 \cdot 1$ & 9.9 \\
\hline
\end{tabular}

- Shorthand designation: the number before the colon indicates the total number of carbon atoms, and the zero after the colon indicates the absence of double bonds. The prefixes indicate iso (i) or anteiso (a) branching.

+ Probably including $\mathrm{i}-12: 0, \mathrm{i}-15: 0,3-\mathrm{OH}-\mathrm{i}-11: 0$, and dehydration products from the hydroxy acids.

14:0. Strain NCIB 10472 was exceptional in also containing significant proportions of 3-OH-i$12: 0$ and $3-\mathrm{OH}-\mathrm{i}-14: 0$, as well as small proportions of acids tentatively identified as $3-\mathrm{OH}-\mathrm{a}-$ $13: 0$ and $3-\mathrm{OH}-\mathrm{a}-15: 0$. The proportions of the major non-hydroxy acids $(13: 0$ and $\mathrm{i}-13: 0)$ varied with the strain, though the possibility that profiles may have been distorted by selective loss of the more volatile methyl esters cannot be discounted.

\section{Fractionation of the LPSS}

Mild acid hydrolysis. Hydrolysis with $1 \%(\mathrm{v} / \mathrm{v})$ acetic acid at $100{ }^{\circ} \mathrm{C}$ was used to release lipid A, by selective cleavage of the ketosidic linkage to KDO. Sephadex chromatography of the watersoluble products gave somewhat varied elution profiles, but in no case was polymeric material detected by screening, and the amounts of material eluted before the fractions detected were negligible.

The products from the LPS of strain NCIB 10471 were cleanly resolved on Sephadex G-50 into two fractions ( $F 1$ and $F 2$ ), both containing carbohydrate and phosphorus (Fig. 1). This behaviour was comparable with that found for strain NCIB 8768, the other group I strain (Wilkinson et al., 1973). The phosphorylated oligosaccharide in the F1 fraction had $m_{\mathrm{P}_{\mathrm{f}}} 0.30$ on paper electrophoresis at $\mathrm{pH} 5 \cdot 3$, gave a positive reaction with ninhydrin, and was only partly degraded on treatment with alkaline phosphatase.

The hydrolysis products of LPSs from the remaining strains were incompletely resolved on Sephadex G-15 (e.g. Fig. 2) or even on Sephadex G-10. Also, in these cases the initial (F1) carbohydrate peaks in the elution profiles were not matched by similar peaks in the phosphorus profiles. Thus, in contrast to group I LPSs, those of other groups appear to have core oligosaccharides which lack phosphate residues, or contain phosphate residues which are exceptionally acid-labile. As the elution profiles (Figs 1 and 2) show, much of the phosphate in all LPSs is indeed acid-labile and is released as products described below.

Oligosaccharide fractions. Analysis of the presumed core oligosaccharide (F1) fractions for neutral and amino sugars (Table 3) showed that galactose was a major component in all cases and that galactosamine was present in the products from strains NCIB 10472, NCIB 10473, and 


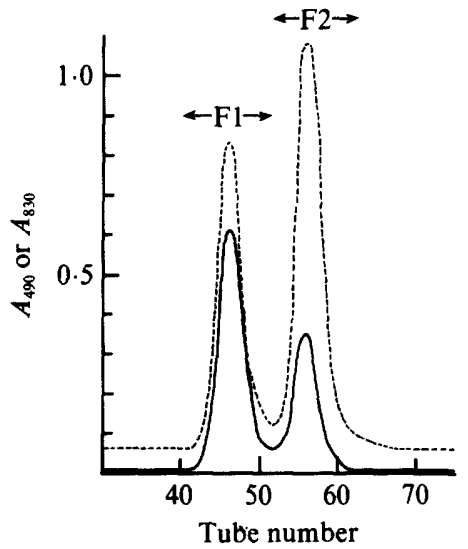

Fig. 1

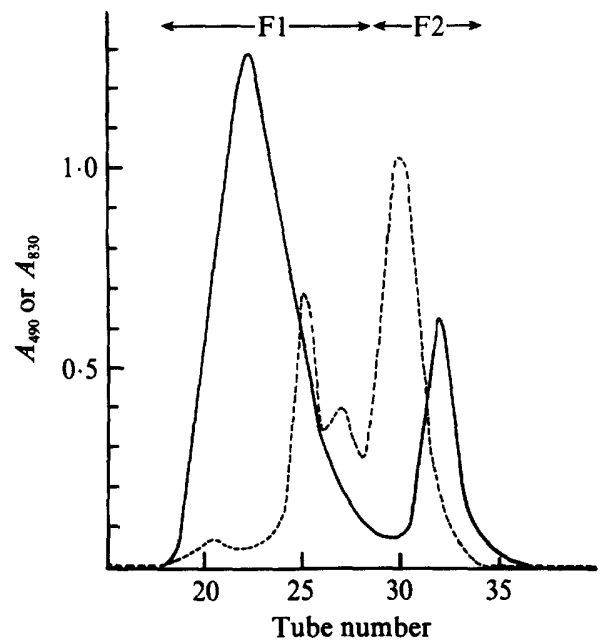

Fig. 2

Fig. 1. Fractionation of water-soluble products from mild acid hydrolysis of the LPS from strain NCIB 10471. Products from the LPS $(192 \mathrm{mg})$ were applied to a column $(2.5 \times 58 \mathrm{~cm})$ of Sephadex G50 and eluted with aqueous pyridine/acetic acid buffer (pH 5.4) at $17 \mathrm{ml} \mathrm{h}^{-1}$. Fractions (4 ml) were analysed for carbohydrate by the phenol/ $\mathrm{H}_{2} \mathrm{SO}_{4}$ method (-) and for phosphorus (--- ). Fractions were pooled as indicated (F1, F2).

Fig. 2. Fractionation of water-soluble products from mild acid hydrolysis of the LPS from strain NCTC 10763. Products from the LPS $(275 \mathrm{mg})$ were applied to a column $(1.5 \times 80 \mathrm{~cm})$ of Sephadex G15 and eluted with aqueous pyridine/acetic acid buffer (pH 5.4) at $10 \mathrm{ml} \mathrm{h}^{-1}$. Fractions ( $\left.2 \mathrm{ml}\right)$ were analysed for carbohydrate (-) and for phosphorus (---), and were pooled as indicated. A similar profile was obtained for the products from strain NCIB 10473, except that the carbohydrate peak in the F2 fraction was smaller and preceded the phosphorus peak. When larger fractions $(3 \mathrm{ml})$ were collected in similar studies of the products from strains NCIB 10472, NCTC 10737 and NCIB 11156, elution profiles were again similar but resolution of the low- $M_{\mathrm{r}}$ phosphates was lost.

\section{Table 3. Neutral and amino sugar composition $(\%, w / w)$ of the putative core oligosaccharides}

Partly degraded core oligosaccharide fractions (F1) were obtained by Sephadex chromatography of water-soluble products from mild acid hydrolysates of the LPSs. Because of contamination by products of lower $M_{\mathrm{r}}$, the numerical data for all fractions except that from strain NCIB 10471 are lower than they should be.

\section{Component}

\section{D-Galactose}

D-Glucose

D-Galactosamine

3-Amino-3,6-dideoxyglucose*

Quinovosamine*

Heptose

\begin{tabular}{cccc}
\multicolumn{4}{c}{ Strain: } \\
NCIB 10471 & NCIB 10472 & NCIB 10473 & NCTC 10763 \\
$16 \cdot 1$ & 36.3 & $29 \cdot 8$ & 21.8 \\
$12 \cdot 1$ & 0 & 0 & 0 \\
0 & $10 \cdot 0$ & $11 \cdot 1$ & 11.9 \\
$13 \cdot 2$ & 0 & 0 & 0 \\
0 & 0 & 0 & 2.6 \\
+ & $(+)$ & $(+)$ & +
\end{tabular}

* Results were obtained by autoanalysis and are expressed as glucosamine.

NCTC 10763. The product from strain NCIB 10471 also contained glucose and 3-amino-3,6dideoxyglucose, while quinovosamine was a minor component for strain NCTC 10763 and a major component $(17.5 \%$ of F1) for strain NCTC 10738. No fraction contained more than a trace of glucosamine, showing that this hexosamine was confined to lipid A. Curiously, very little heptose was detected by GLC of the alditol acetates from the F1 fractions of strains NCIB 10472 and NCIB 10473, even though significant amounts had been detected by application of the same methods to the parent LPSs. 
Examination of the ${ }^{1} \mathrm{H}$ NMR spectra of the oligosaccharides showed that the amino sugar components were present as their $N$-acetyl derivatives, giving a sharp singlet at about $\delta 2.05$. It was also evident that the oligosaccharides from the NCIB strains 10472 and 10473 had the same structure as well as composition (Table 3), giving essentially identical NMR spectra. Structural studies on these oligosaccharides are in progress.

Monosaccharide products. Mild acid hydrolysis of some LPSs produced significant amounts of material of low $M_{\mathrm{r}}$ reactive in the phenol/ $\mathrm{H}_{2} \mathrm{SO}_{4}$ assay. In the case of strain NCIB 10471, this material was largely $(88 \%$ ) free D-galactose, as previously found for the other group I strain NCIB 8768 (Wilkinson et al., 1973). A comparison of the galactose :glucose ratios for whole LPS and the $F 1$ fraction indicated that about half of the total galactose had been released. Little or no galactose was present in the F2 fractions from the remaining six LPSs.

The phenol/ $\mathrm{H}_{2} \mathrm{SO}_{4}$ reactivity associated with the $\mathrm{F} 2$ fractions for strains NCIB 10473, NCIB 11156 and NCTC 10737 was mainly attributable to free galacturonic acid, and this acid was also present in the F2 fraction for strain NCTC 10763.

In contrast to other F2 fractions, the carbohydrate in the F2 fraction from strain NCTC 10763 was eluted after $P_{i}$ (Fig. 2). It consisted predominantly of free D-fructose, identified by an extensive range of chromatographic and colorimetric methods and by enzymic assay. Because fructose is not commonly found in bacterial LPSs, a second group IV strain (NCTC 10738) was also examined for this sugar. It was again present in the F2 fraction, though in a smaller amount.

Phosphates. As shown in Fig. 1, the relatively high value of $M_{\mathrm{r}}$ for the phosphorylated core oligosaccharide from strain NCIB 10471 made possible a clean separation from other phosphorus-containing products on Sephadex G-50. The major product in the F2 fraction was $\mathbf{P}_{\mathrm{i}}$, but ethanolamine phosphate and ethanolamine pyrophosphate were also detected.

Phosphorus-containing degradation products from other LPSs were incompletely resolved from the core oligosaccharide even on Sephadex G-15 (e.g. Fig. 2). When the fractions collected were sufficiently small $(2 \mathrm{ml})$, two distinct peaks on the phosphorus profile were detected before that for $P_{i}$ (the main phosphate in the $F 2$ fractions, along with ethanolamine phosphate). Electrophoretic examination of the F1 fractions and calibration of the column indicated that the two early phosphorus peaks corresponded to $\mathrm{PP}_{\mathrm{i}}$ (especially abundant for strain NCTC 10763) and ethanolamine pyrophosphate. Supporting evidence for the latter was the formation of ethanolamine phosphate and $\mathrm{P}_{\mathrm{i}}$ (about $60 \%$ of the total phosphorus) on acid hydrolysis ( $1 \mathrm{M}$ $\mathrm{HCl}, 100{ }^{\circ} \mathrm{C}, 7 \mathrm{~min}$ ), and the formation of ethanolamine and $\mathrm{P}_{\mathrm{i}}$ on treatment with alkaline phosphatase. The $\mathrm{PP}_{\mathrm{i}}$ was further identified by TLC (solvent system J) and by hydrolysis with pyrophosphatase.

Results similar to those described above for strains NCIB 10472, NCIB 10473 and NCTC 10763 were also obtained for the low- $M_{\mathrm{r}}$ phosphates from the LPSs of strains NCTC 10737 and NCIB 11156. However, the LPS from strain NCTC 10738 contained relatively little phosphorus $(1 \cdot 3 \%)$, and $\mathrm{P}_{\mathrm{i}}$ was the only phosphate detected after mild acid hydrolysis.

\section{DISCUSSION}

The results of this study, involving eight strains of $A$. putrefaciens representing four different DNA-DNA homology groups, indicate that the organism produces only R-type LPSs, among which both unifying and differentiating structural features are apparent. The results of the previous study of strain NCIB 8768 (Wilkinson et al., 1973) showed that residues of phosphorylated glucosamine formed the backbone of lipid A, and it seems likely that all strains are conventional in this respect. On the other hand, the exceptionally complex array of fatty acids in lipid A (common to strains of different groups) is a highly distinctive characteristic of the LPSs of $\boldsymbol{A}$. putrefaciens. Other distinctive structural features are the presence of D-glycero-Dmanno-heptose and of cryptic KDO. It seems very likely that a single KDO residue forms the link between the core oligosaccharide and lipid A, and that difficulty in detecting this residue by the periodate/thiobarbituric acid assay can be attributed partly to phosphorylation and partly to 
glycosylation (Caroff et al., 1987a,b). The fact that most core oligosaccharides were obtained virtually free of phosphorus further suggests that elimination of phosphate residues (possibly $P_{i}$, $\mathrm{PP}_{\mathrm{i}}$, or ethanolamine phosphates) had occurred from the 4-position of KDO during the mild acid hydrolysis (Caroff et al., 1987 b). The failure to detect $\mathrm{KDO}$ or any other periodate/thiobarbituric acid-reactive compound in the $\mathrm{F} 2$ fractions of mild hydrolysates indicates the absence from the core region of the lateral KDO substituents found in some enterobacterial LPSs (Tacken et al., 1986).

Other notable features of the LPSs of $A$. putrefaciens are the occurrence of acid-labile residues of D-galactose (group I strains), D-fructose (group IV strains), and D-galacturonic acid (most marked in group II and group III strains, NCIB 10472 excepted). In the case of strain NCIB 8768, almost all of the galactose is released by mild acid hydrolysis (Wilkinson $e t$ al., 1973), but in the case of strain NCIB 10471 a second (acid-stable) galactose residue seems to be present. Although the present study was too limited in scope for group-specific features to be identified with certainty, other possibilities lie in the amino sugar components of the core oligosaccharides. Galactosamine was absent only from the group I strains, while 3-amino-3,6dideoxyglucose, which is a major component for strain NCIB 10471 (Table 3), may be the minor component of strain NCIB 8768 tentatively identified as fucosamine (Wilkinson et al., 1973). Similarly, quinovosamine seems to be restricted to the core oligosaccharides of group IV strains: a major component for strain NCTC 10738 but a minor one for strain NCTC 10763 (the reverse of the relative abundance of fructose in the two strains). The origins of the acid-labile sugar residues and the reasons for their facile release have yet to be determined.

Another feature which distinguishes the core oligosaccharides of the group I strains from those of other strains with a low mol \% GC in their DNA (45-48\%, groups II and III), as well as the group IV strains $(52-55 \mathrm{~mol} \% \mathrm{GC}$ ), is the presence of acid-stable phosphate residues (probably attached to heptose). All of the LPSs (except that from strain NCTC 10738) are rich in phosphate residues which are released under conditions of acid hydrolysis that do not cause excessive breakdown of pyrophosphates. The preliminary evidence that the core oligosaccharides from strain NCIB 10472 (group II) and strain NCIB 10473 (group III) are depleted in heptose and probably have the same structure adds further intrigue to the chemistry of the LPSs of these organisms, and enhances the chemotaxonomic interest of these studies.

Little is known of the LPSs of other Alteromonas species, but the product from Alteromonas haloplanktis contains mainly straight-chain, even-carbon fatty acids (DiRienzo \& MacLeod, 1978), in marked contrast with $A$. putrefaciens (Table 2). Similar contrasts for the fatty acid profiles of extractable lipids between $\boldsymbol{A}$. putrefaciens and other alteromonads (Wilkinson \& Caudwell, 1980; Moule \& Wilkinson, 1987; Monteoliva-Sanchez \& Ramos-Cormenzana, 1987) indicate that the LPSs are unlikely to be similar in fatty acid composition. Significant differences between $\boldsymbol{A}$. putrefaciens, $\boldsymbol{A}$. haloplanktis, $\boldsymbol{A}$. macleodii, and other alteromonads have also been revealed by numerical taxonomy (Lee et al., 1977; Gray \& Stewart, 1980), and by studies of rRNA cistrons (Van Landschoot \& De Ley, 1983), superoxide dismutases (DeLong et al., 1984), and lipid components (Wilkinson \& Caudwell, 1980; Moule \& Wilkinson, 1987). Discordance in the fatty acid profiles remains if $A$. putrefaciens is placed in the family Vibrionaceae as Shewanella putrefaciens (MacDonell \& Colwell, 1985). However, it is intriguing to note that 3-amino-3,6-dideoxy-L-glucose is a component of the core oligosaccharide in LPSs from Vibrio anguillarum and Aeromonas hydrophila (Banoub \& Shaw, 1981), and of an O-specific polysaccharide of the former species (Banoub et al., 1987). Like A.putrefaciens, these organisms are also located in subgroup $\gamma-3$ of the purple bacteria (Woese et al., 1985). However, although group I strains of $\boldsymbol{A}$. putrefaciens may have the same 3-amino sugar as a core component, the oligosaccharides differ in other respects, e.g. the presence of acid-stable phosphate, the nature of the heptose. Hopefully, structural studies of the core oligosaccharides from strains representing the different groups of $\boldsymbol{A}$. putrefaciens will clarify the extent of intraspecific heterogeneity and the systematics of the organisms.

We thank the Science and Engineering Research Council for a research studentship (A.L.M.), Miss L. Galbraith for technical assistance, Mr A. D. Roberts for GLC/MS, and Dr. L. Szabó (Université de Paris-Sud, 
Orsay) for information and advice on the HF-treatment of LPSs. Reference amino sugars were kindly provided by Dr A. C. Richardson (University of London), Dr G. Ashwell (National Institutes of Health, Bethesda), and Dr M. B. Perry (National Research Council of Canada, Ottawa). Mr J. Brown, Mr P. F. Caudwell and Miss R. Garton participated in preliminary studies of some LPSs.

\section{REFERENCES}

Ashwell, G., Brown, N. C. \& VolK, W. A. (1965). A colorimetric procedure for the determination of $\mathrm{N}$ acetylated-3-amino hexoses. Archives of Biochemistry and Biophysics 112, 648-652.

Banoub, J. H. \& ShaW, D. H. (1981). Isolation and characterization of 3-acetamido-3,6-dideoxy-Lglucose from the core oligosaccharides obtained from the aquatic gram-negative bacteria Aeromonas hydrophila and Vibrio anguillarum. Canadian Journal of Biochemistry 59, 877-879.

BaNoub, J. H., Michon, F. \& Hodder, H. J. (1987). Structural elucidation of the $O$-specific polysaccharide of the phenol-phase soluble lipopolysaccharide of Vibrio anguillarum. Canadian Journal of Biochemistry and Cell Biology 65, 19-26.

BARTletT, G. R. (1959). Phosphorus assay in column chromatography. Journal of Biological Chemistry 234, 466-468.

Baumann, P., Gauthier, M. J. \& Baumann, L. (1984). Genus Alteromonas. In Bergey's Manual of Systematic Bacteriology, vol. 1, pp. 343-352. Edited by N. R. Krieg. Baltimore \& London: Williams \& Wilkins.

BlumenKRaNTZ, N. \& Asboe-Hansen, G. (1973). New method for quantitative determination of uronic acids. Analytical Biochemistry 54, 484-489.

BoRATYŃskI, J. (1984). Colorimetric method for the determination of ketoses using phenol-acetone-boric acid reagent (PABR). Analytical Biochemistry 137, 528-532.

BRYN, K. \& JANTZEN, E. (1982). Analysis of lipopolysaccharides by methanolysis, trifluoroacetylation, and gas chromatography on a fused-silica capillary column. Journal of Chromatography 240, 405-413.

BRYN, K. \& JANTZEN, E. (1986). Quantification of 2keto-3-deoxyoctonate in (lipo)polysaccharides by methanolytic release, trifluoroacetylation and capillary gas chromatography. Journal of Chromatography 370, 103-112.

Caroff, M., Lebbar, S. \& SZabó, L. (1987a). Do endotoxins devoid of 3-deoxy-D-manno-2-octulosonic acid exist? Biochemical and Biophysical Research Communications 143, 845-847.

Caroff, M., LebBar, S. \& Szabó, L. (1987b). Detection of 3-deoxy-2-octulosonic acid in thiobarbiturate-negative endotoxins. Carbohydrate Research 161, c4-c7.

Crumpton, M. J. (1959). Identification of amino sugars. Biochemical Journal 72, 479-486.

Dawson, R. M. C., Elliott, D. C., Elliott, W. H. \& JONES, K. M. (1986). Data for Biochemical Research, 3rd edn, pp. 475-476. Oxford: Oxford University Press.

DeLong, E. F., BaumanN, L., Bowditch, R. D. \& BAUMANN, P. (1984). Evolutionary relationships of superoxide dismutases and glutamine synthetases from marine species of Alteromonas, Oceanospirillum, Pseudomonas and Deleya. Archives of Microbiology 138, 170-178.
DiRienzo, J. M. \& Macleod, R. A. (1978). Composition of the fractions separated by polyacrylamide gel electrophoresis of the lipopolysaccharide of a marine bacterium. Journal of Bacteriology 136, 158167.

Dische, Z. \& Borenfreund, E. (1951). A new spectrophotometric method for the detection and determination of keto sugars and trioses. Journal of Biological Chemistry 192, 583-587.

Drewry, D. T., Gray, G. W. \& Wilkinson, S. G. (1971). Release of ethanolamine pyrophosphate during mild acid hydrolysis of the lipopolysaccharide of Pseudomonas aeruginosa. European Journal of Biochemistry 21, 400-403.

Drewry, D. T., Gray, G. W. \& Wilkinson, S. G. (1972). Low-molecular-weight solutes released during mild acid hydrolysis of the lipopolysaccharide of Pseudomonas aeruginosa. Biochemical Journal 130, 289-295.

Dubois, M., Gilles, K. A., Hamilton, J. K., Rebers, P. A. \& SMITH, F. (1956). Colorimetric method for determination of sugars and related substances. Analytical Chemistry 28, 350-356.

Erbing, C., LindBerg, B. \& Svensson, S. (1973). Deamination of methyl 2-amino-2-deoxy- $\alpha$ - and - $\beta$-Dglucopyranosides. Acta chemica scandinavica 27, 3699-3704.

GILARDI, G. L. (1985). Cultural and biochemical aspects for identification of glucose-nonfermenting gram-negative rods. In Nonfermentative Gram-Negative Rods. Laboratory Identification and Clinical Aspects, pp. 34-37. Edited by G. L. Gilardi. New York \& Basel: Marcel Dekker.

Gray, P. A. \& Stewart, D. J. (1980). Numerical taxonomy of some marine pseudomonads and alteromonads. Journal of Applied Bacteriology 49, 375-383.

VAN HANDEL, E. (1967). Determination of fructose and fructose-yielding carbohydrates with cold anthrone. Analytical Biochemistry 19, 193-194.

HANES, C. S. \& IsHERWoOd, F. A. (1949). Separation of the phosphoric esters on the filter paper chromatogram. Nature, London 164, 1107-1112.

HELANDER, I. M. (1985). Isolation and electrophoretic analysis of bacterial lipopolysaccharides. In Enterobacterial Surface Antigens. Methods for Molecular Characterisation, pp. 263-274. Edited by T. K. Korhonen, E. A. Dawes \& P. H. Mäkelä. Amsterdam: Elsevier.

ITAYA, K. \& UI, M. (1965). Colorimetric determination of free fatty acids in biological fluids. Journal of Lipid Research 6, 16-20.

LEE, J. V. (1979). Alteromonas (Pseudomonas) putrefaciens. In Cold Tolerant Microbes in Spoilage and the Environment, pp. 59-65. Edited by A. D. Russell \& R. Fuller. London: Academic Press.

LeE, J. V., Giason, D. M. \& Shewan, J. M. (1977). A numerical taxonomic study of some Pseudomonas- 
like marine bacteria. Journal of General Microbiology 98, 439-451.

Lee, J. V., Gibson, D. M. \& Shewan, J. M. (1981). Alteromonas putrefaciens sp. nov. International Journal of Systematic Bacteriology 31, 215-218.

LINDBERG, B. \& LöNNGREN, J. (1978). Methylation analysis of complex carbohydrates: general procedure and application for sequence analysis. Methods in Enzymology 50C, 3-33.

L'vov, V. L., Tochtamysheva, N. V., ShashKov, A. S., DMtTriev, B. A. \& CĂPEK, K. (1983). 3-[( $N$ Acetyl-L-seryl)amino]-3,6-dideoxy-D-glucose: a novel constituent of a bacterial antigenic polysaccharide. Carbohydrate Research 112, 233-239.

MacDonell, M. T. \& Colwell, R. R. (1985). Phylogeny of the Vibrionaceae, and recommendation for two new genera, Listonella and Shewanella. Systematic and Applied Microbiology 6, 171-182.

ManN, A. F., Hucklesby, D. P. \& Hewit, E. J. (1979). A modified Hanes and Isherwood spray for improved detection of phosphate esters in thin layer chromatography. Analytical Biochemistry 96, 6.

Monteoliva-Sanchez, M. \& Ramos-Cormenzana, A. (1987). Cellular fatty acid composition in moderately halophilic Gram-negative rods. Journal of Applied Bacteriology 62, 361-366.

Moule, A. L. \& Wilkinson, S. G. (1987). Polar lipids, fatty acids, and isoprenoid quinones of Alteromonas putrefaciens (Shewanella putrefaciens). Systematic and Applied Microbiology 9, 192-198.

OhNo, N., Suzuki, I. \& Yadomae, T. (1985). A method for monitoring elution profiles during the chromatography of amino sugar-containing oligo- and polysaccharides. Carbohydrate Research 137, 239-243.

OsBorN, M. J. (1963). Studies on the Gram-negative cell wall. I. Evidence for the role of 2-keto-3-deoxyoctonate in the lipopolysaccharide of Salmonella typhimurium. Proceedings of the National Academy of Sciences of the United States of America 50, 499-506.

Owen, R. J., Legros, R. M. \& Lapage, S. P. (1978). Base composition, size and sequence similarities of genome deoxyribonucleic acids from clinical isolates of Pseudomonas putrefaciens. Journal of General Microbiology 104, 127-138.

PARvin, R. \& SMITH, R. A. (1969). Determination of inorganic phosphate in the presence of labile organic phosphates. Analytical Biochemistry 27, 65-72.
Rondle, C. J. M. \& Morgan, W. T. J. (1955). The determination of glucosamine and galactosamine. Biochemical Journal 61, 586-589.

SeltMANN, G. \& BeER, W. (1985). Vorkommen von 3Amino-3,6-didesoxy-D-glucose in einem Lipopolysaccharid von Campylobacter coli. Journal of Basic Microbiology 25, 551-552.

Sempere, J. M., Gancedo, C. \& Asensio, C. (1965). Determination of galactosamine and $\mathrm{N}$-acetylgalactosamine in the presence of other hexosamines with galactose oxidase. Analytical Biochemistry 12, 509515.

TACKen, A., Rietschel, E. T. \& Brade, H. (1986). Methylation analysis of the heptose/3-deoxy-Dmanno-2-octulosonic acid region (inner core) of the lipopolysaccharide from Salmonella minnesota rough mutants. Carbohydrate Research 149, 279-291.

VAN LANDSCHOOT, A. \& DE LeY, J. (1983). Intra- and intergeneric similarities of the rRNA cistrons of Alteromonas, Marinomonas (gen. nov.) and some other Gram-negative bacteria. Journal of General Microbiology 129, 3057-3074.

WARREN, L. (1960). Thiobarbituric acid spray reagent for deoxy sugars and sialic acids. Nature, London 186, 237.

WiLkINson, S. G. (1977). Composition and structure of bacterial lipopolysaccharides. In Surface Carbohydrates of the Prokaryotic Cell, pp. 97-175. Edited by I. W. Sutherland. London: Academic Press.

Wilkinson, S. G. \& Caudwell, P. F. (1980). Lipid composition and chemotaxonomy of Pseudomonas putrefaciens (Alteromonas putrefaciens). Journal of General Microbiology 118, 329-341.

Wilkinson, S. G., Galbraith, L. \& Lightfoot, G. A. (1973). Cell walls, lipids, and lipopolysaccharides of Pseudomonas species. European Journal of Biochemistry 33, 158-174.

Woese, C. R., Weisburg, W. G., Hahn, C. M., Paster, B. J., ZABlen, L. B., Lewis, B. J., Macke, T. J., Ludwig, W. \& STACKebrandT, E. (1985). The phylogeny of purple bacteria: the gamma subdivision. Systematic and Applied Microbiology 6, 25-33.

Wright, B. G. \& Rebers, P. A. (1972). Procedure for determining heptose and hexose in lipopolysaccharides. Modification of the cysteine-sulfuric acid method. Analytical Biochemistry 49, 307-319. 